\title{
The effect of motivational interviewing-based intervention using self-determination theory on promotion of physical activity among women in reproductive age: A randomized clinical trial
}

\author{
Seyed Saeed Mazloomy Mahmoodabad ${ }^{1}$, Nooshin Rouhani Tonekaboni ${ }^{2}$, Rabiollah Farmanbar ${ }^{3}$, Hossein \\ Fallahzadeh $^{4}$, Tahereh Kamalikhah ${ }^{5}$
}

${ }^{1}$ Ph.D. of Health Education, Professor, Department of Health Education and Promotion, School of Public Health, Shahid Sadoughi University of Medical Sciences, Yazd, Iran

${ }^{2}$ Ph.D. Candidate of Health Education and Health Promotion, Department of Health Education and Promotion, School of Public Health, Shahid Sadoughi University of Medical Sciences, Yazd, Iran

${ }^{3}$ Ph.D. of Health Education, Associate Professor, Department of Health Education and Health Promotion, School of Health, Guilan University of Medical Sciences, Rasht, Iran

${ }^{4}$ Ph.D. of Biostatistics, Professor, Department of Biostatistics and Epidemiology, School of Public Health, Shahid Sadoughi University of Medical Sciences, Yazd, Iran

${ }^{5}$ Ph.D. of Health Education and Health Promotion, Assistant Professor, Department of Health Education and Health Promotion, Semnan University of Medical Sciences, Semnan, Iran

\section{Type of article: Original}

\begin{abstract}
Background: Physical activity (PA) prevents chronic diseases. Self-determination theory (SDT) provides a useful framework to understand the nature of motivational interviewing (MI).

Objective: This study aimed to determine the effect of MI-based intervention using SDT on the promotion of PA among women in reproductive age.

Methods: Seventy women in reproductive age were selected by clustering sampling method for this randomized controlled trial. The questionnaire included the variables of physical fitness test, SDT, and global physical activity questionnaire (GPAQ). The validity of the questionnaires was approved using content validity ratio (CVR) and index (CVI). The reliability and internal consistency of the questionnaires and measures was approved using test-retest method and Cronbach's alpha test, respectively. The intervention group $(n=35)$ received four MI sessions through theory and one standard education session about PA. The control group $(n=35)$ received a standard education session about PA.

Results: Four months after the intervention, an increase in the mean scores of total PA $(p<0.001, E S=4.77)$, physical fitness tests including flexibility $(\mathrm{p}<0.001, \mathrm{ES}=1.59)$, muscular endurance $(\mathrm{p}<0.001, \mathrm{ES}=2.0)$, cardiorespiratory endurance $(\mathrm{p}<0.001, \mathrm{ES}=0.51)$, and a decrease in mean scores of agility test $(\mathrm{p}<0.001, \mathrm{ES}=-$ $0.51)$ and sedentary behavior $(\mathrm{p}<0.01, \mathrm{ES}=-0.74)$ was observed in the intervention group compared to the control group. The intervention group reported an increase in the scores of intrinsic motivation $(\mathrm{p}<0.001, \mathrm{ES}=3.34)$, identified regulation $(\mathrm{p}<0.001, \mathrm{ES}=1.28)$, perceptions of competence $(\mathrm{p}<0.001, \mathrm{ES}=0.81)$ and autonomy $(\mathrm{p}<0.001, \mathrm{ES}=2.01)$, enjoyment $(\mathrm{p}<0.001, \mathrm{ES}=0.98)$ and health motives $(\mathrm{p}<0.01, \mathrm{ES}=0.19)$, health care climate $(\mathrm{p}<0.001, \mathrm{ES}=4.6)$, and a decreased score of external regulation $(\mathrm{p}<0.01, \mathrm{ES}=-0.55)$ and amotivation $(\mathrm{p}<0.01$, $\mathrm{ES}=-0.56$ ) over time, compared to the control group.

Conclusion: MI-based intervention using SDT was effective on the promotion of PA.

Trial registration: The Trial was registered at the Iranian Registry of Clinical Trial (http://www.irct.ir) with the Irct ID: IRCT2015101924592N1.
\end{abstract}

Keywords: Motivational interviewing, Physical activity, Women

\section{Corresponding author:}

Nooshin Rouhani Tonekaboni, Department of Health Education and Promotion, School of Public Health, Shahid Sadoughi University of Medical Sciences, Yazd, Iran.

Tel: +98.9111944587, Fax: +98.3538209119, Email: rouhani.phd@gmail.com

Received: December 05, 2016, Accepted: January 30, 2017, Published: May 2017

iThenticate screening: January 24, 2017, English editing: February 09, 2017, Quality control: April 11, 2017

(C) 2017 The Authors. This is an open access article under the terms of the Creative Commons Attribution-NonCommercialNoDerivs License, which permits use and distribution in any medium, provided the original work is properly cited, the use is non-commercial and no modifications or adaptations are made. 


\section{Introduction}

Physical activity (PA) refers to all movements made by skeletal muscles that cause energy consumption, and includes activities at work, home and leisure time (sport) (1). The recommended level of regular PA includes 30 minutes of moderate activity 5 days a week, or 20 minutes of intense activity 3 days a week (2). Insufficient levels of PA have been reported as 48.6 to 91 percent in some Iranian studies (3-5), and it was found that women have less PA than men (5-6). However, PA can prevent the incidence of obesity, osteoporosis, anxiety, depression, colon cancer and breast cancer in women or reduce their risk (7-10). Preventive intervention among women in their reproductive age (before menopause), provides an essential basis for good health and proper life in the years after menopause (11). MI can be defined as a form of client-centered cooperative guide to elicit and enhance motivation for change (12) through discovery, identification and resolution of doubts and ambivalence. Its aim is to create a suitable atmosphere, until the client becomes the main supporter of change, as the primary factor for the change (13). Counselors provide required information and support for change, and propose alternative approaches and potential ways of change. In MI, a counselor does not directly encourage or force the client to change, but leaves the client in making decisions to change, or not to change. A counselor's role in this process, is to help clients in order to identify their contradictory motivations (14). Recently, Rollnik et al. (15), have identified the four underlying principles of MI: 1) Resistance of the righting reflex, 2) Understanding client's motivation, 3) Listening to client and 4) Empowering client. SDT (16) is a wide psychological theory to help better understand health behavior (17). One of its basic principles is that human motivation changes within an autonomous (when individuals behave in a perfect sense of willingness and choice) or a controlled (when individuals behave under internal and external pressure) range through a continuum. Identified regulation (means performing a behavior because it seems important and useful) and intrinsic motivation (means performing a behavior because of its intrinsic satisfaction) show more autonomous forms of motivation. In contrast, introjected regulation (behaving in a way to prevent negative emotions such as anxiety or guilt), external regulation (behaving in a way to achieve a tangible reward, to avoid punishment or force of an external power) show more controlled forms of motivation. SDT also pays attention to amotivation (i.e. people do not see any connection between behavior and its consequences). Satisfaction of psychological needs is an important theoretical variable that is presumed to facilitate the autonomous forms of motivation (16). These needs include autonomy (i.e. independence in choosing behavior or activity) (18), competence (i.e. the feelings of individuals about efficacy to behavior) (19), and relatedness (i.e. the feeling of connection with others) (19). Another construct of SDT is the health care climate, which specifies the support of perceived needs of individuals (20). Moreover, the individuals' reasons for doing exercise are important in determining the continuous compliance to regular PA. External motives, such as doing exercise to control weight or on a doctor's advice, can be understood as a controller that weakens self-determination. Conversely, intrinsic motivations, such as exercise for enjoyment, can be understood as promoters of self-determination perceptions (21). Some studies have stated some counterparts between the MI and SDT in detail. Foote et al. (22) Ginsberg, Mann, Rotgers, and Weekes (23) showed that MI can be formed and conceptualized by the SDT (24). SDT provides a useful theoretical framework to understand the mechanism of effectiveness of MI (25). This study aimed to determine the effect of MI-based intervention using SDT on Promotion of Physical Activity among women in the reproductive age who visited health centers in Tonekabon, Mazandaran, Iran. This randomized controlled trial conducted by the pre-test, post-test and follow-up within 4 months in two intervention and control groups with a sample size of 35 cases in each group.

\section{Material and Methods}

\subsection{Trial design and participants}

This study was a randomized clinical trial that was conducted from October 2014 to February 2015. After obtaining the permission of the health authority, we re-called the women in reproductive age to the health center and explained the objectives of the study. The samples were randomly divided into two groups: the intervention group $(\mathrm{n}=35)$ received educational content through $\mathrm{MI}$ and general education; the control group $(\mathrm{n}=35)$ received only educational content based on general education. At the end, the number of samples was decreased to 30-31 people in each group. Sampling process was performed with randomized cluster method. Since Tonekabon has 4 urban health centers, each of these centers was considered as a cluster. Of the 4 urban health centers, 2 were randomly chosen by randomized sampling for the intervention group $(\mathrm{n}=35)$; and the 2 other centers were chosen by randomized sampling for the control group $(\mathrm{n}=35)$.

\subsection{Instruments}

Instruments consisted of subjective instruments (demographic questionnaire, SDT-based instruments, and GPAQ), and objective Instruments (for assessing Body Mass Index, and physical fitness-based instruments). Demographic information included age, educational level, job, and spouse's job. Physical fitness-based instruments included 
flexibility test, muscular endurance test, agility test, and cardiorespiratory endurance test. SDT-based instruments included behavioral regulation in the exercise questionnaire, questionnaire of satisfaction with psychological need, scale of Motivation for Physical Activity-revised (MPAM-R), and health care climate questionnaire.

\subsubsection{Behavioral regulation in exercise questionnaire}

The behavioral regulation in exercise questionnaire (BREQ-2) (26) was used to assess motivation for PA. Its validity and reliability have been confirmed in previous study (27). This scale was used to evaluate the reasons why people do exercise or participate in a physical activity. BREQ-2 includes subscales of assessment of intrinsic motivation, identified regulation, introjected regulation, external regulation, and amotivation. Participants responded to each item on a five-point Likert-scale, from zero (it is not totally true about me) to 4 (it is completely true about me). $\mathrm{CVR}=0.83-0.95, \mathrm{CVI}=0.61-86.2$, reliability coefficient $=0.72-0.83$, and Cronbach's alpha $=0.72-0.84$ was for these sub-scales. The mean scores of 5 subscales were calculated on a five-point scale to create a reflection of the extent of each type of motivation separately. It is placed on self-determination continuum specifically. Relative Autonomy Index (RAI), shows the relative autonomy. RAI is assessed by summing weighted scores for each subscale: (intrinsic motivation $\times+3)+($ identified regulation $\times+2)+($ introjected regulation $\times-1)+($ external regulation $\times-2)$ $+($ amotivation $\times-3)(28)$.

\subsubsection{The Psychological Need Satisfaction in Exercise Scale}

This scale (29) evaluates the perception of autonomy, competence, and dependency. Each item is measured on a 6 point Likert scale, from 1 (absolutely not true) to 6 (absolutely true). CVR=0.63-0.67, CVI=0.81-0.83, reliability coefficient $=0.84-0.89$, and Cronbach's alpha $=0.74-0.86$ was for these sub-scales.

2.2.3. The Scale of motivation for Physical Activity - revised (MPAM-R)

It is a revised version of MPAM (30), which was developed by Ryan et al. in 1997 (31). It evaluates five general motivations about participating in PA, including: enjoyment, challenge, appearance, preparation/health and social motives. Each field is estimated on a 7-point Likert scale (low=1, high=7). CVR=0.65-0.71, CVI=0.83-0.91, reliability coefficient $=0.77-0.86$, and Cronbach's alpha $=0.71-0.95$ was for these sub-scales.

\subsubsection{Health care climate questionnaire}

This scale was developed by Williams et al. (32). It measures the perceptions about the degree to which their health care providers were supporters or controllers of autonomy. Responses to each item was estimated on a 7-point Likert scale ranging from $1=$ strongly disagree to $7=$ strongly agree. $\mathrm{CVR}>0.67, \mathrm{CVI}=0.83-0.92$, reliability coefficient $=$ 0.82 , and Cronbach's alpha $=0.95$ was for these sub-scales.

\subsubsection{GPAQ}

PA level (activities at work, commuting and leisure as well as sedentary behavior) was measured using GPAQ (33). Participants were asked "how much time do they spend on intense activities at workplace within a typical day or week? And how many days do they continuously commute walking or cycling, for at least 10 minutes?" The obtained information was collected according to GPAQ analysis guide (34), and the value of MET - minute per week was estimated. Moderate and intense PA courses were calculated by an energy equivalent index of MET $=4$, $\mathrm{MET}=8$, respectively (35). METS (Metabolic equivalents) are used to express the intensity of physical activity. One MET is defined as energy consumption, and it is equal to the consumption of $1 \mathrm{kal} / \mathrm{kg} /$ hour. Reliability coefficient was 0.82 .

\subsubsection{Body Mass Index (BMI)}

BMI was calculated by dividing weight (in kilograms) by height squared (in meters) (36).

\subsubsection{Flexibility test}

Subjects were required to sit on the ground without shoes and in sport clothes, with legs extended and straight, in a way that the backs of their knees (popliteal) were completely flush to the ground, and the soles of both feet were contacted vertically to a test board, which they then tried to lead the tips of their fingers towards the calibrated wood, by bending forward and holding it at the farthest possible point for 2 seconds

Each test was done 3 times and the best record was used as the degree of flexibility (37).

\subsubsection{Muscular endurance test}

The muscular endurance was measured with sit-up test (38). In this test, subjects laid on their back with knees bent and hands passing the upper chest. A tester holds the subjects' legs, ready to count the moves. At first, the subjects should get high enough, so that their forearms touch the quadriceps muscle, and for the next movement their shoulders should touch the floor. In the present study, the number of sit-ups in 30 seconds made up the muscular endurance test.

\subsubsection{Agility test}

To assess general agility, $9 \times 4$ test was used. In this test, the subjects covered a distance of 9 meters, four times at high speed; the duration of the test was recorded in seconds and tenths of a second from start to finish time (39). 


\subsubsection{Cardiorespiratory endurance test}

To assess cardiorespiratory endurance, maximal oxygen uptake was measured. For this purpose, Quinn step test was used, which is a physiologic index, to measure PA. In this test, the subject is required to step up and down on a 41$\mathrm{cm}$ step for 3 minutes. Rhythm per minute for women is 22 beats per minute. Immediately after completion of the activity, the subjects sit and their heart rate is counted for 15 seconds from 5 seconds to 20 . Validity and reliability of the test has been proven in various studies (40-42). Maximal oxygen uptake was calculated using the following formula: $[(4 \times$ heart rate $) \times 0.1847]-65.81=$ Maximal oxygen uptake

\subsection{Selection criteria}

The Inclusion criteria were women aged between 15-49 years, married, willing to attend regular training sessions and the women having the least ability to read and write. Women with the mentioned characteristics and those with PA less than regular level (according to the categorization of GPAQ questionnaire) participated in the study. The Exclusion criteria were pregnant women, patients with major diseases and orthopedic problems and lack of adherence to the intervention program.

\subsection{Interventions}

In this study, the independent variable was MI, which was done in groups. Miller and Rollnik believe that since many effective intervention strategies are better offered in groups in health centers, the implementation of MI in groups has a better clinical justification (13). Therefore, in this study, the samples were divided into groups including 10-12 individuals. Before starting the MI sessions, a public training session was held about the generalities of regular PA (types and amounts), and the benefits of regular PA were mentioned for the intervention and control groups; at the end of the session, a training pamphlet including session summary was given to group members. An educational program was held in 4 sessions of MI with 90 minutes per session for the intervention group (43). Educational sessions were held at an urban health center. Before the sessions, the necessary arrangements were made with group members. At the beginning of each session, the researcher checked the present-absent participants and at the end of each session, the exact time of the next session was mentioned. Available studies and instructions in theses and articles were used in designing the training program sessions (Table1) $(43,44)$.

\subsection{Outcomes}

The primary outcome of our analysis was the rate of self-determination theory components. Also, the secondary outcome from the analysis was the effectiveness of self-determination theory components on PA and physical fitness.

\subsection{Sample size}

The sample size was estimated to be 70 women. It was calculated based on the results of previous studies (45) by considering $\alpha=5 \%$, the statistical power of $80 \%$. Considering drop up sample, we added 10 samples to the calculated sample size, so we considered 70 samples totally.

\subsection{Statistical methods}

The first assessment or pre-test was performed before starting the intervention, using subjective and objective instruments. The second assessment or post-test was performed immediately after finishing the intervention just using subjective instruments; the final assessment or follow-up was performed four months after finishing the intervention using subjective and objective instruments. SPSS version 16 (SPSS Inc., Chicago, Illinois, USA) was used to analyze the data. The two-tail value of $\mathrm{p}<0.05$ was determined as statistically significant. We used descriptive statistics, chi-squared, independent $t$ test, paired t test, repeated measure, Friedman, covariance, and $\mathrm{U}$ Mann-Whitney tests to analyze the primary and secondary outcome.

\subsection{Research ethics}

This study was approved by the Ethics Committee of Shahid Sadoughi University of Medical Sciences. Participation in the study was completely voluntary. Participants read and signed the informed consent forms prior to the study. Also, each of the participants could be excluded from the study at any time during the program. Furthermore, confidentiality of all participants' information was ensured. 
Table 1. Intervention program in MI sessions

\begin{tabular}{|c|c|}
\hline Sessions & Description of the intervention \\
\hline \multirow{3}{*}{$\begin{array}{l}\text { First session: Introducing the motivational } \\
\text { approach, facilitators' philosophy, and group } \\
\text { principles- with an emphasis on the principle of } \\
\text { avoiding the intention to reform the client }\end{array}$} & Knowing motivational approach \\
\hline & $\begin{array}{l}\text { Knowing the facilitator philosophy (supporting the } \\
\text { autonomy) }\end{array}$ \\
\hline & Determining rules and norms of the group \\
\hline \multirow{2}{*}{$\begin{array}{l}\text { Second session: Studying a single day of } \\
\text { subject's life in terms of the amount of PA and } \\
\text { the effects of physical inactivity }\end{array}$} & $\begin{array}{l}\text { Increasing participants' awareness about the quantity and } \\
\text { quality of their PA behavior }\end{array}$ \\
\hline & $\begin{array}{l}\text { Increasing participants' awareness about the effects of } \\
\text { physical inactivity }\end{array}$ \\
\hline \multirow{4}{*}{$\begin{array}{l}\text { Third session: Values and negative and positive } \\
\text { aspects-with an emphasis on the perception of } \\
\text { client's motivation. }\end{array}$} & Participants identify their values \\
\hline & $\begin{array}{l}\text { Participants recognize how their values are in conflict } \\
\text { with their sedentary behavior. }\end{array}$ \\
\hline & $\begin{array}{l}\text { Participants recognize the positive and negative aspects of } \\
\text { sedentary behavior. }\end{array}$ \\
\hline & $\begin{array}{l}\text { Participants determine the importance and the value of } \\
\text { positive and negative aspects }\end{array}$ \\
\hline \multirow{5}{*}{$\begin{array}{l}\text { Fourth session: Temptation and self-confidence, } \\
\text { goal setting and preparing for change - with an } \\
\text { emphasis on the principle of empowering the } \\
\text { clients }\end{array}$} & $\begin{array}{l}\text { Participants become familiar with the basis of creation of } \\
\text { temptation }\end{array}$ \\
\hline & $\begin{array}{l}\text { Participants identify the situations where much temptation } \\
\text { is created to quit the regular program of PA. }\end{array}$ \\
\hline & Participants identify situations with confidence \\
\hline & Participants learn how to set appropriate goals \\
\hline & $\begin{array}{l}\text { Subjects express goals and write a change layout for its } \\
\text { realization }\end{array}$ \\
\hline
\end{tabular}

\section{Results}

Seventy women in reproductive age were randomly assigned to the randomized controlled trial. With Chi-squared test, no significant difference was observed between intervention and control groups regarding the demographic characteristics (age, educational level, job, spouse's job) and body composition ( $\mathrm{p}>0.05$ ).

\subsection{SDT components}

The results of the psychological variables of SDT are shown in Table 2. With repeated measures test, the intervention group showed a higher level of autonomy, identified regulation, perception of competence, challenge and enjoyment motives through time than before the intervention. Friedman's non-parametric test also showed an increased intrinsic motivation, introjected regulation, perception of self-determination and fitness/health motive and a reduction in amotivation in the intervention group compared to before intervention over time (Table 2). Comparing the intervention and control groups within 4 months, variables such as intrinsic motivation, identified regulation, perception of autonomy, perception of competence and perception of relatedness, enjoyment motive, and health care climate, indicated moderate to high effect sizes. Conversely, introjected regulation, external regulation, amotivation and fitness/health, challenge, social and appearance motives, showed low or negative effect sizes (Table 3).

\subsection{Physical activity and sedentary behavior}

With repeated measures tests, the participants in the intervention group showed a higher level of PA over time and a lower level of sedentary behavior in the non-parametric Friedman test compared to pre-intervention time (Table 2). Within 4 months after intervention, the subjects in the intervention group showed higher level of PA with high effect size and lower level of sedentary behavior with negative effect size compared with the control group.

\subsection{Body composition and physical fitness tests}

In the intervention group, the repeated measures tests showed a significant reduction in body mass index, and paired t-test showed a significant increase in body flexibility, muscle endurance, and cardiorespiratory endurance and a significant reduction in agility score over time (Table 2). The subjects in the intervention group indicated lower scores of body mass index and agility, with a negative effect size and higher levels of cardiorespiratory endurance, muscular endurance and flexibility of the body with medium to high effect sizes, in 4 months after intervention compared with the control group (Table 4). 
http://www.ephysician.ir

Table 2. Comparison of SDT Components, Physical fitness tests, total PA and sedentary behaviors during the assessment process.

\begin{tabular}{|c|c|c|c|c|}
\hline Variables & $\begin{array}{l}\text { Mean } \pm \text { SD of Pre-test; } \\
\text { Intervention (control) }\end{array}$ & $\begin{array}{l}\text { Mean } \pm \text { SD of Post- } \\
\text { test; Intervention } \\
\text { (control) }\end{array}$ & $\begin{array}{l}\text { Mean } \pm \text { SD of Follow } \\
\text { up after } 4 \text { months; } \\
\text { Intervention (control) }\end{array}$ & $\begin{array}{l}\text { p-value; } \\
\text { Intervention }^{1} \\
\left(\text { control }^{1}\right)\end{array}$ \\
\hline Intrinsic Motivation & $\begin{array}{l}3.03 \pm 1.47 \\
(4.32 \pm 1.95)\end{array}$ & $\begin{array}{l}10.80 \pm 2.0 \\
(4.90 \pm 1.88)\end{array}$ & $\begin{array}{l}13.50 \pm 1.79 \\
(5.51 \pm 2.39)\end{array}$ & $<0.001(<0.001)$ \\
\hline Identified Regulation & $\begin{array}{l}6.43 \pm 2.19 \\
(8.19 \pm 2.61)\end{array}$ & $\begin{array}{l}10.66 \pm 1.72 \\
(8.48 \pm 2.36)\end{array}$ & $\begin{array}{l}12.03 \pm 1.60 \\
(8.58 \pm 2.68)\end{array}$ & $<0.001(>0.05)$ \\
\hline $\begin{array}{l}\text { Introjected } \\
\text { Regulation }\end{array}$ & $\begin{array}{l}1.40 \pm 1.52 \\
(2.29 \pm 1.83)\end{array}$ & $\begin{array}{l}3.20 \pm 2.65 \\
(2.93 \pm 2.23)\end{array}$ & $3.33 \pm 2.78(3.29 \pm 1.81)$ & $<0.001(>0.05)$ \\
\hline External Regulation & $\begin{array}{l}0.13 \pm 0.43 \\
(0.32 \pm 0.17)\end{array}$ & $\begin{array}{l}0.30 \pm 0.79 \\
(0.38 \pm 0.98)\end{array}$ & $0.43 \pm 1.04(1.19 \pm 1.37)$ & $>0.05(<0.001)$ \\
\hline Amotivation & $\begin{array}{l}0.93 \pm 2.46 \\
(0.61 \pm 1.28)\end{array}$ & $\begin{array}{l}0.33 \pm 1.06 \\
(0.70 \pm 1.24)\end{array}$ & $0.06 \pm 0.36(0.58 \pm 0.92)$ & $<0.05(>0.05)$ \\
\hline $\begin{array}{l}\text { Relative Autonomy } \\
\text { Index }\end{array}$ & $4.04 \pm 0.24(6 \pm 0.26)$ & $\begin{array}{l}11.59 \pm 0.23 \\
(6.27 \pm 2.17)\end{array}$ & $\begin{array}{l}14.25 \pm 2.35 \\
(6.04 \pm 0.26)\end{array}$ & $<0.001(>0.05)$ \\
\hline $\begin{array}{l}\text { Perception of } \\
\text { Autonomy }\end{array}$ & $15.60 \pm 4(20.14 \pm 5.17)$ & $\begin{array}{l}26.60 \pm 4.43 \\
(19.89 \pm 4.56)\end{array}$ & $\begin{array}{l}30.40 \pm 2.83 \\
(19.85 \pm 5.24)\end{array}$ & $<0.001(>0.05)$ \\
\hline $\begin{array}{l}\text { Perception of } \\
\text { Competence }\end{array}$ & $\begin{array}{l}12.20 \pm 3.66 \\
(15.71 \pm 5.53)\end{array}$ & $\begin{array}{l}13.6 \pm 3.05 \\
(14.71 \pm 3.87)\end{array}$ & $\begin{array}{l}17.20 \pm 3.46 \\
(14.10 \pm 3.82)\end{array}$ & $<0.01(>0.05)$ \\
\hline $\begin{array}{l}\text { Perception of } \\
\text { Relatedness }\end{array}$ & $13.36 \pm 1.01(13 \pm 8.34)$ & $\begin{array}{l}13.10 \pm 7.38 \\
(12.89 \pm 6.85)\end{array}$ & $\begin{array}{l}15.63 \pm 7.61 \\
(12.14 \pm 6.21)\end{array}$ & $>0.05(>0.05)$ \\
\hline Enjoyment motive & $20 \pm 9.36(28.28 \pm 4.75)$ & $\begin{array}{l}27.30 \pm 6.77 \\
(26 \pm 4.68)\end{array}$ & $30 \pm 3.83(24.89 \pm 5.20)$ & $<0.001(<0.05)$ \\
\hline Appearance motive & $\begin{array}{l}19.80 \pm 9.44 \\
(24.82 \pm 6.38) \\
\end{array}$ & $\begin{array}{l}20.26 \pm 8.88 \\
(23.39 \pm 6.68)\end{array}$ & $\begin{array}{l}20.96 \pm 8.40 \\
(23.03 \pm 6.94) \\
\end{array}$ & $>0.05(>0.05)$ \\
\hline Fitness/health motive & $\begin{array}{l}20.06 \pm 8.04 \\
(23.92 \pm 3.36)\end{array}$ & $\begin{array}{l}23.23 \pm 6.19 \\
(23.21 \pm 3.33)\end{array}$ & $\begin{array}{l}25.73 \pm 3.02 \\
(25.32 \pm 1.10)\end{array}$ & $<0.001(>0.05)$ \\
\hline Challenge motive & $15 \pm 7.25(18.25 \pm 6.12)$ & $\begin{array}{l}16.80 \pm 6.34 \\
(16.75 \pm 5.66)\end{array}$ & $\begin{array}{l}17.90 \pm 5.17 \\
(16.46 \pm 5.38)\end{array}$ & $<0.001(>0.05)$ \\
\hline Social motive & $\begin{array}{l}13.83 \pm 6.88 \\
(13.03 \pm 4.15)\end{array}$ & $\begin{array}{l}13.43 \pm 5.94 \\
(12.60 \pm 5.49)\end{array}$ & $\begin{array}{l}12.90 \pm 5.73 \\
(12.35 \pm 5.34)\end{array}$ & $>0.05(>0.05)$ \\
\hline Health care climate & $\begin{array}{l}77.56 \pm 1.32 \\
(72.25 \pm 1.54)\end{array}$ & $\begin{array}{l}80.50 \pm 9.97 \\
() 69.89 \pm 1.59\end{array}$ & $\begin{array}{l}83.10 \pm 1.37 \\
(69.57 \pm 1.61)\end{array}$ & $>0.05(>0.05)$ \\
\hline BMI & $\begin{array}{l}26.04 \pm 3.37 \\
(26.44 \pm 3.59)\end{array}$ & $\begin{array}{l}25.78 \pm 3.30 \\
(26.53 \pm 3.53)\end{array}$ & $\begin{array}{l}25.32 \pm 3.05 \\
(26.59 \pm 3.53)\end{array}$ & $<0.001(>0.05)$ \\
\hline Flexibility & $\begin{array}{l}31.46 \pm 6.88 \\
(27.35 \pm 5.95)\end{array}$ & - & $\begin{array}{l}35.53 \pm 5.87 \\
(26.83 \pm 5.47)\end{array}$ & $<0.001(>0.05)$ \\
\hline Muscular endurance & $\begin{array}{l}13.30 \pm 3.03 \\
(12.51 \pm 3.16)\end{array}$ & - & $\begin{array}{l}17.83 \pm 2.70 \\
(12.48 \pm 2.90)\end{array}$ & $<0.001(>0.05)$ \\
\hline Agility & $\begin{array}{l}15.58 \pm 1.89 \\
(13.78 \pm 1.17)\end{array}$ & - & $\begin{array}{l}13.21 \pm 1.44 \\
(13.80 \pm 1.14)\end{array}$ & $<0.001(>0.05)$ \\
\hline $\begin{array}{l}\text { Cardiorespiratory } \\
\text { endurance }\end{array}$ & $\begin{array}{l}36.39 \pm 3.20 \\
(37.99 \pm 2.24)\end{array}$ & - & $\begin{array}{l}39.10 \pm 2.76 \\
(37.99 \pm 2.14) \\
\end{array}$ & $<0.001(>0.05)$ \\
\hline $\begin{array}{l}\text { Total Physical } \\
\text { activity (Met- } \\
\text { min/Week) }\end{array}$ & $\begin{array}{l}361.33 \pm 98.11 \\
(477.85 \pm 108.91)\end{array}$ & $\begin{array}{l}487.33 \pm 111.47 \\
(453.57 \pm 60.87)\end{array}$ & $\begin{array}{l}854 \pm 271.60 \\
(470 \pm 80.46)\end{array}$ & $<0.001(>0.05)$ \\
\hline $\begin{array}{l}\text { Sedentary behavior } \\
\text { (hour/day) }\end{array}$ & $\begin{array}{l}5.61 \pm 2.65 \\
(5.45 \pm 2.04)\end{array}$ & $\begin{array}{l}5.28 \pm 2.34 \\
(5.75 \pm 2.34)\end{array}$ & $4.26 \pm 1.76(5.91 \pm 2.21)$ & $<0.001(<0.05)$ \\
\hline
\end{tabular}

1: p-value is reported for comparison within intervention group during times; $2: \mathrm{p}$-value is reported for comparison within control group during times 
Table 3. Characteristics of SDT components, PA and sedentary behaviors within 4 months after the intervention by groups

\begin{tabular}{|l|l|l|l|l|}
\hline \multirow{2}{*}{ Variables } & \multicolumn{2}{|l|}{ Follow up after 4 months; Mean \pm SD } & p-value & ES $^{1}$ \\
\cline { 2 - 3 } & Intervention & Control & & \\
\hline Intrinsic Motivation & $13.50 \pm 1.79$ & $5.51 \pm 2.39$ & $<0.001^{2}$ & 3.34 \\
\hline Identified Regulation & $12.03 \pm 1.60$ & $8.58 \pm 2.68$ & $<0.001^{3}$ & 1.28 \\
\hline Introjected Regulation & $3.33 \pm 2.78$ & $3.29 \pm 1.81$ & $0.5^{2}$ & 0.02 \\
\hline External Regulation & $0.43 \pm 1.04$ & $1.19 \pm 1.37$ & $0.002^{2}$ & -0.55 \\
\hline Amotivation & $0.06 \pm 0.36$ & $0.58 \pm 0.92$ & $0.004^{2}$ & -0.56 \\
\hline Relative Autonomy Index & $14.25 \pm 2.35$ & $6.04 \pm 0.26$ & $<0.001^{3}$ & 3.52 \\
\hline Perception of Autonomy & $30.40 \pm 2.83$ & $19.85 \pm 5.24$ & $<0.001^{2}$ & 2.01 \\
\hline Perception of Competence & $17.20 \pm 3.46$ & $14.10 \pm 3.82$ & $0.001^{3}$ & 0.81 \\
\hline Perception of Relatedness & $15.63 \pm 7.61$ & $12.14 \pm 6.21$ & $0.082^{2}$ & 0.1 \\
\hline Enjoyment motive & $30 \pm 3.83$ & $24.89 \pm 5.20$ & $<0.001^{3}$ & 0.98 \\
\hline Appearance motive & $20.96 \pm 8.40$ & $23.03 \pm 6.94$ & $0.252^{3}$ & -0.2 \\
\hline Fitness/health motive & $25.73 \pm 3.02$ & $25.32 \pm 1.10$ & $0.003^{2}$ & 0.19 \\
\hline Challenge motive & $17.90 \pm 5.17$ & $16.46 \pm 5.38$ & $0.36^{3}$ & 0.26 \\
\hline Social motive & $12.90 \pm 5.73$ & $12.35 \pm 5.34$ & $0.78^{3}$ & 0.1 \\
\hline Health care climate & $83.10 \pm 1.37$ & $69.57 \pm 1.61$ & $0.001^{3}$ & 4.6 \\
\hline Total Physical activity (Met-min/Week) & $854 \pm 271.60$ & $470 \pm 80.46$ & $<0.001^{3}$ & 4.77 \\
\hline Sedentary behavior (hour/day) & $4.26 \pm 1.76$ & $5.91 \pm 2.21$ & $0.002^{2}$ & -0.74 \\
\hline
\end{tabular}

1: Effect Size, 2: U Mann-Whitney test, 3: t-test

Table 4. Characteristics of BMI and physical fitness sizes within 4 months after intervention by groups

\begin{tabular}{|l|l|l|l|l|}
\hline \multirow{2}{*}{ Variables } & \multicolumn{2}{|l|}{ Follow up after 4 months; Mean \pm SD } & \multirow{2}{*}{-value } & ES \\
\cline { 2 - 3 } & Intervention & Control & & \\
\hline BMI & $25.32 \pm 3.05$ & $26.59 \pm 3.53$ & $0.13^{1}$ & -0.35 \\
\hline Flexibility & $35.53 \pm 5.87$ & $26.83 \pm 5.47$ & $<0.001^{2}$ & 1.59 \\
\hline Muscular endurance & $17.83 \pm 2.70$ & $12.48 \pm 2.90$ & $<0.001^{1}$ & 2.0 \\
\hline Agility & $13.21 \pm 1.44$ & $13.80 \pm 1.14$ & $<0.001^{2}$ & -0.51 \\
\hline Cardiorespiratory endurance & $39.10 \pm 2.76$ & $37.99 \pm 2.14$ & $<0.001^{2}$ & 0.51 \\
\hline
\end{tabular}

1: t-test, 2: Covariance test

\section{Discussion}

The main objective of this study was to assess the impact of MI-based intervention on PA among women in reproductive age. The next objective was to examine some psychological variables of SDT that play an important role in these effects. For this purpose, 70 women in reproductive age were randomly assigned to the randomized controlled trial. In this study, the mean score of the overall PA (moderate + intense) was increased four months after the intervention in intervention group compared with the control group, with the change from 90.33 minutes mean in a week before the intervention, to 213.5 minutes per week in the four following months. In a similar study (45-47), the mean score of PA was also increased over time in the intervention group. While this change was not observed in the control group. Behavior is a complex issue and several factors are involved. Effective education can change unhealthy behavior in order to achieve healthy behavior, but this process needs time. The mean score of sedentary behavior between the intervention and control groups showed a significant difference within four months after the intervention, and a negative effect size was observed which was lower in the intervention group than the control group. The mean score was decreased overtime in the intervention group and changed from 5.61 hours a day preintervention to 4.26 hours a day, four months after the intervention, while no change was observed in the control group. According to the evidence (48), if the amount of daily sedentary behavior reaches to four hours or more, people are considered as sedentary. So, in this regard, a decreased sedentary behavior in the intervention group members was created over time, but a little more is needed to achieve the desired level. So, in future educational programs, this important issue must be considered in order to increase PA. The mean score of intrinsic motivation components between intervention and control groups within the 4 months after intervention had a significant difference, and high effect size was identified. The mean score of intrinsic motivation indicated a significant increase over time in the intervention group, while the control group indicated a brief increase. Similar results were found in other studies $(45,49)$. According to the principles of MI and SDT, having intrinsic motivation in 
performing PA is an important factor in the onset and continuity of this behavior. Increased intrinsic motivation confirms an increase in internalization process of autonomy regulation of PA by intervention over time. The mean score of amotivation within four months after intervention, was less than the control group. Similar findings were observed in the study conducted by Gourlan et al. (46). While in the study of Sweet et al. (49) there was no significant difference between groups. The mean score of amotivation was also decreased in the intervention group over time. The amotivation had a negative relationship with performing behavior. If the lack of motivation decreases, the probability of intervention success in creating motivation for performing activity will increase. The mean score of relative autonomy index between intervention and control groups had a significant difference within four months after the intervention and indicated high effect size. The mean score was increased in the intervention group over time, while there was no significant difference in the control group. In other studies (47), selfdetermination index had no significant difference over time in the intervention group. While a significant difference was observed in the mean autonomy index within three different periods of time in the control group with a decreasing process. According to these findings, the more autonomy index increases overtime, the more success will be obtained in the intervention program, and onset and continuity of PA will have more progress. Several studies clearly showed that autonomy in behavior is a crucial predictor of long term and sustainable behavior change (50). This is also true in case of exercise, where research has shown that more autonomous motivations will result in longer-term commitment to PA (51). In this study, the mean score of perception of autonomy and competence had a significant difference between intervention and control groups within 4 months, which was identified with high effect size. In the intervention group, the satisfaction with needs was increased over time, but there was no significant difference in the control group. Similar findings were also observed in other studies $(45,52)$, through the follow up period; while another study (47) indicated no significant difference in the mean score of perception of autonomy in the intervention group, and it was decreased in the control group. Increasing the perception of autonomy is one of the important aims of MI. Perception of the autonomy means the independency in choosing a behavior (18). In this case, the individual chooses a behavior by their own decision and interest, and performs the behavior in their own way (53). This issue is an important factor in the onset and continuity of a behavior. Perception of competence indicates the individual's capabilities (54). In this case, individuals believe that doing exercise will bring the desired results, and feel like they are capable and competent, and have constant participation in behavior (25). The mean score of perception of relatedness between intervention and control group had no significant difference within 4 months after intervention. Also, no change was observed over time in intervention and control groups; this finding is consistent with the study of Levy \& Cardinal (55) that after the intervention, no increase was reported in relatedness. While in another study (47), perception of relatedness in exercise behavior had significant difference in intervention and control groups in different periods of time. Similar results were also reported in the study of Edmond et al. (53).

In the intervention group, the mean score of enjoyment motive was increased after 4 months, while it was decreased in the control group, and the effect size of intervention was identified as high for this variable. Also, enjoyment motive was increased in the intervention group over time, whereas it was decreased in the control group. Internal motivations, such as doing exercise for fun, can be understood as increased perception of self-determination (21). In agreement with the principles of MI, the present intervention had a great emphasis on the promotion of perception of autonomy, which will consequently lead to an increase in enjoyment motive. The mean score of appearance motive in the intervention group was less than the control group within 4 months, while it was not significant. The mean score had no significant difference in intervention and control groups over time. But in the study of Silva et al. (45), the appearance motive had a significant difference in intervention and control groups after one year of follow-up, so that it was higher in the intervention group. But the effect size of intervention was reported as 0.35. External motives, such as exercise for weight control, can be perceived as a controlled motive by which self-determination becomes less and causes lack of enjoyment of exercise (21). In this study, the mean score of health care climate 4 months after intervention, was higher in the intervention group than the control group, which was identified with high effect size. This finding was consistent with the results of similar studies (45 and 46). In this study, the mean BMI in the intervention group was reduced over time. In a study conducted by Gourlan, the intervention group reported a decrease in the BMI three months after the intervention, while no difference was observed 6 months after the intervention (46). Although a significant decrease was found in the mean BMI, people are still in the overweight range. Commitment to regular PA is one way of gaining desirable weight. Other factors are also involved, such as appropriate nutrition. A significant difference was observed in the mean score of body flexibility, muscular endurance and cardiorespiratory endurance between the intervention and control groups within four months after the intervention, and showed a high and moderate effect size. The mean score was increased in the intervention group four months after the intervention, compared to pre-intervention. No difference was observed in the control group. 
In the study of Fathi (56), on the effect of six weeks of aerobic exercise on cardiovascular endurance, body composition, flexibility etc. among female students, there was no significant increase in flexibility score after the intervention, and the difference in results is due to the short training course or also insufficient intensity and type of exercise. In the study by Anbari et al. (57), the mean score of abdominal muscle endurance in sit-ups was increased in the intervention group after the intervention. Also in the study by Gourlan et al. (46), the energy consumption also had a significant difference between groups in different times; energy consumption was weaker in the intervention group before to the intervention. Compared with the control group, energy consumption was increased in the intervention group over time. There was a significant difference in the mean score of agility test $(4 \times 9$ sprint $)$ between the two groups within four months after the intervention, so that the score was lower in the intervention group and the effect size was negative. In the intervention group, the mean score was significantly decreased compared to the pre-intervention, and the duration of exercise reduced to 13.21 seconds from 15.58 seconds within four months after the intervention. No difference was observed in the control group, and similar results were reported in the other studies $(57,58)$. The study had some limitations. First, the nature of the control group limited the direct comparison of intervention with other PA promotion programs. Decision making about choosing the standard control group was related to other objectives of this trial, that enable us to perceive the mechanisms strengthening self-determined motivation for PA. While demographic variables and some SDT variables had no difference in two groups at the baseline, the possibility of differences between the groups at baseline cannot be absolutely prohibited. One of the prominent points in this study was the objective measurement to evaluate PA using physical fitness tests and measuring body's composition through measuring height and weight tests to measure BMI, which reduces the errors induced by self-report measurement. Finally, the results of the present study, showed that the intervention has been performed well and that it caused significant changes in PA, body composition, and physical fitness of women in reproductive age.

\section{Conclusions}

The results showed that designing an MI-based intervention using SDT can promote the PA. Therefore, informing health educators about this educational method would be useful in offering interventions aimed at promoting PA among women in reproductive age.

\section{Acknowledgments:}

The present study is obtained from a specified $\mathrm{PhD}$ course thesis. Hereby, the cooperation of all women in the reproductive age from Tonekabon during the study and the cooperation of authorities and employees of health centers in Tonekabon who issued sampling and testing of their clients, are highly appreciated. Also, we are thankful for the help and guidance of Dr. Mohammad Ali Rahmani in this study.

\section{Trial registration:}

The Trial was registered at the Iranian Registry of Clinical Trial (http://www.irct.ir) with the Irct ID: IRCT2015101924592N1.

\section{Funding:}

The authors received financial support for the research from Shahid Sadoughi University of Medical Sciences.

\section{Conflict of Interest:}

There is no conflict of interest to be declared.

\section{Authors' contributions:}

All authors contributed to this project and article equally. All authors read and approved the final manuscript.

\section{References:}

1) Gagne M, Ryan RM, Bargmann K. Autonomy support and need satisfaction in the motivation and wellbeing of gymnasts. Journal of Applied Sport Psychology. 2003; 15(4): 372-90. doi: 10.1080/10413200390238031.

2) Najmabadi KM. Exercise prescription for Iranian midlife women. International journal of general medicine. 2010; 3: 365-9. doi: 10.2147/IJGM.S10807. PMID: 21189832, PMCID: PMC3008288.

3) Esteghamati A, Khalilzadeh O, Rashidi A, Kamgar M, Meysamie A, Abbasi M. Physical activity in Iran: results of the third national surveillance of risk factors of non-communicable diseases (SuRFNCD-2007). J Phys Act Health. 2011; 8(1): 27-35. doi: 10.1123/jpah.8.1.27. PMID: 21297182. 
4) Momenan A, Delshad M, Mirmiran P, Ghanbarian A, Safarkhani M, Azizi F. Physical inactivity and related factors in an adult Tehranian population (Tehran Lipid and Glucose Study). Iranian Journal of Endocrinology and Metabolism. 2012; 13(5): 493-503.

5) Maddah M, Akbarian Z, Shoyooie S, Rostamnejad M, Soleimani M. Prevalence of regular exercise among Iranian adults: a study in northern iran. J Phys Act Health. 2014; 11(4): 810-3. doi: 10.1123/jpah.20120202. PMID: 23575214.

6) Motefaker M, Sadrbafghi SM, Rafiee M, Bahadorzadeh L, Namayandeh SM, Karimi M, et al. Epidemiology of physical activity; a population based study in yazd city. Tehran University Medical Journal. 2007; 65(4): 77-81.

7) Verloop J, Rookus MA, Van Der Kooy K, Van Leeuwen FE. Physical activity and breast cancer risk in women aged 20-54 years. J Natl Cancer Inst. 2000; 92: 128-35. doi: 10.1093/jnci/92.2.128. PMID: 10639514.

8) Friedenreich CM. Physical Activity and Cancer: lessons learned from nutritional epidemiology. Nutr Rev. 2014; 59(11): 349-57. doi: 10.1111/j.1753-4887.2001.tb06962.x. PMID: 11720340.

9) Kull M. The relationships between physical activity, health status and psychological well - being of fertility - aged women. Scand J Med Sci Sports. 2002; 12(4): 241-7. doi: 10.1034/j.16000838.2002.00341.x. PMID: 12199874.

10) Housley E, Leng GC, Donnan PT, Fowkes FG. Physical activity and risk of peripheral arterial disease in the general population: Edinburgh Artery Study. J Epidemiol Community Health. 1993; 47(6): 475-80. doi: 10.1136/jech.47.6.475. PMID: 8120503, PMCID: PMC1059862.

11) Khandwala SS. Primary care of the perimenopausal woman. Primary care update for OB/GYNS. 1998; 5(1): 43-9. doi: 10.1016/S1068-607X(97)00123-6.

12) Miller WR, Rollnick S. Ten things that motivational interviewing is not. Behav Cogn Psychother. 2009; 37(2): 129-40. doi: 10.1017/S1352465809005128. PMID: 19364414.

13) Miller W, Rollnick S. Motivational interviewing: Preparing people for change behavior. 2nd The Guilford Press: New York; 2002.

14) Miller WR. Motivational interviewing with problem drinkers. Behavioural psychotherapy. 1983; 11: 14772. doi: 10.1017/S0141347300006583.

15) Rollnick S, Miller WR, Butler CC, Aloia MS. Motivational interviewing in health care: helping patients change behavior. Journal of Chronic Obstructive Pulmonary Disease. 2008; 5(3): 203. doi: $10.1080 / 15412550802093108$.

16) Deci EL, Ryan RM. Handbook of self-determination research. Rochester, NY: University of Rochester Press; 2002.

17) Ng J, Ntoumanis N, Thogersen-Ntoumani C, Deci EL, Ryan RM, Duda JL, et al. Self-determination theory applied to health contexts: A meta-analysis. Perspectives on Psychological Science. 2012; 7: 325-40. doi: $10.1177 / 1745691612447309$.

18) Vlachopoulos SP. The basic psychological needs in exercise scale: measurement invariance over gender. Structural Equation Modeling. 2008; 15(1): 114-35. doi: 10.1080/10705510701758398.

19) Ryan RM, Deci EL. An overview of self-determination theory: an organismic-dialectical perspective. In Deci EL, Ryan RM (Eds.). Handbook of self-determination research. Rochester, NY: University of Rochester Press; 2002; 3-33.

20) Ryan RM, Deci EL. Self-determination theory and the facilitation of intrinsic motivation, social development, and well-being. Am Psychol. 2000; 55(1): 68-78. doi: 10.1037/0003-066X.55.1.68. PMID: 11392867.

21) Markland D. Internally informational versus internally controlling exercise motives and exercise enjoyment: The mediating role of self-determination. In. Parisi P, Pigozzi F, Prinzi G (Eds), Sport Science '99 in Europe: Proceedings of the 4th annual congress of the European College of Sport Science (p. 214). 1999. Rome: University Institute of Motor Sciences.

22) Foote J, Deluca A, Magura S, Warner A, Grand A, Rosenblum A, et al. A group motivational treatment for chemical dependency. J Subst Abuse Treat. 1999; 17: 181-92. doi: 10.1016/S0740-5472(99)00003-3. PMID: 10531624.

23) Ginsburg JI, Mann RE, Rotgers F, Weekes JR. Motivational interviewing with criminal justice populations. Motivational interviewing: Preparing people for change. Guilford Press; 2002: 333-46.

24) Ryan RM, Edward LD. A Motivational Approach to Self: Integration in Personality. Perspectives on motivation. 1991; 38: 237. 
25) Markland D, Ryan RM, Tobin VJ, Rollnick S. Motivational interviewing and self-determination theory. Journal of social and clinical psychology. 2005; 24(6): 811-31. doi: 10.1521/jscp.2005.24.6.811.

26) Markland D, Tobin V. A modification to the behavioural regulation in exercise questionnaire to include an assessment of amotivation. Journal of Sport and Exercise Psychology. 2004; 26: 191-6. doi: 10.1123/jsep.26.2.191.

27) Farmanbar R, Niknami S, Hidarnia A, Lubans DR. Psychometric Properties of the Iranian Version of the Behavioral Regulation in Exercise Questionnaire-2 (BREQ-2). Health Promot Perspect. 2011; 1(2): 95-104. doi: 10.5681/hpp.2011.010. PMID: 24688905, PMCID: PMC3963623.

28) Verloigne M, De Bourdeaudhuij I, Tanghe A, D'hondt E, Theuwis L, Vansteenkiste M, et al. Selfdetermined motivation towards physical activity in adolescents treated for obesity: an observational study. Int J Behav Nutr Phys Act. 2011; 8: 79. doi: 10.1186/1479-5868-8-97. PMID: 21923955, PMCID: PMC3189862.

29) Wilson PM, Rogers WT, Rodgers WM, Wild TC. The psychological need satisfaction in exercise scale. Journal of Sport and Exercise Psychology. 2006; 28(3): 231-51. doi: 10.1123/jsep.28.3.231.

30) Frederick CM, Ryan RM. Differences in motivation for sport and exercise and their relations with participation and mental health. Journal of sport behavior. 1993; 16(3): 124.

31) Ryan RM, Frederick CM, Lepes D, Noel R, Sheldon KM. Intrinsic motivation and exercise adherence. Int J Sport Psychol. 1997; 28: 335-54.

32) Williams GC, Grow VM, Freedman ZR, Ryan RM, Deci EL. Motivational predictors of weight loss and weight-loss maintenance. J Pers Soc Psychol. 1996; 70(1): 115-26. doi: 10.1037/0022-3514.70.1.115. PMID: 8558405.

33) Armstrong T, Bull F. Development of the World Health Organization global physical activity questionnaire (GPAQ). Journal of Public Health. 2006; 14(2): 66-70. doi: 10.1007/s10389-006-0024-x.

34) WHO. Global physical activity questionnaire (GPAQ) analysis guide. Geneva: World Health Organization; 2012.

35) Hagströmer M, Bergman P, Bauman A, Sjöström M. The International Prevalence Study (Ips): HealthEnhancing Physical Activity In Sweden. Journal of Public Health. 2006; 14(5): 301-8. doi: 10.1007/s10389-006-0032-x.

36) Carpenter CL, Yan E, Chen S, Hong K, Arechiga A, Kim WS, et al. Body fat and body-mass index among a multiethnic sample of college-age men and women. Journal of obesity. 2013. doi: 10.1155/2013/790654.

37) Gaeini AA, Rajabi H. Physical Fitness. Tehran: Samt Press; 2007.

38) Jones D, Robertson L, Figoni S. A strength-endurance index for power grip. J Occup Rehabil. 2009; 19(1): 56-63. doi: 10.1007/s10926-009-9163-6. PMID: 19214717.

39) Hadavi F. Measurement and Evaluation in Physical Education. Tehran: Teacher Training University Press; 1999.

40) Chatterjee S, Chatterjee P, Bandyopadhyay A. Validity of Queen's College Step Test for estimation of maximum oxygen uptake in female students. Indian J Med Res. 2005; 121: 32-5. PMID: 15713976.

41) McArdle WD, Katch FI, Pechar GS, Jacobson L, Ruck S. Reliability and interrelationships between maximal oxygen intake, physical work capacity and step-test scores in college women. Med Sci Sports. 1972; 4(4): 182-6. doi: 10.1249/00005768-197200440-00019. PMID: 4648576.

42) Bandyopadhyay A. Queen's college step test as an alternative of Harvard step test in young Indian women. International Journal of Sport and Health Science. 2008; 6: 15-20. doi: 10.5432/ijdhs.6.15.

43) Poursharifi H. Effectiveness of motivational interviewing on improving health behaviors in adults with Type II diabetes. [dissertation]. [Iran]: Tehran University; 2007.

44) Friederichs SA, Oenema A, Bolman C, Guyaux J, Van Keulen HM, Lechner L. I Move: systematic development of a web-based computer tailored physical activity intervention, based on motivational interviewing and self-determination theory. BMC public health. 2014; 14: 212. doi: 10.1186/1471-2458-14212. PMID: 24580802, PMCID: PMC3944675.

45) Silva MN, Vieira PN, Coutinho SR, Minderico CS, Matos MG, Sardinha LB, et al. Using selfdetermination theory to promote physical activity and weight control: a randomized controlled trial in women. J Behav Med. 2010; 33(2): 110-22. doi: 10.1007/s10865-009-9239-y. PMID: 20012179.

46) Gourlan M, Sarrazin P, Trouilloud D. Motivational interviewing as a way to promote physical activity in obese adolescents: A randomised-controlled trial using self-determination theory as an explanatory framework. Psychol Health. 2013; 28(11): 1265-86. doi: 10.1080/08870446.2013.800518. PMID: 23756082 . 
47) Farmanbar RA, Niknami SA, Heydarnia AR. Effect of an Integrated Transtheoretical Model and SelfDetermination Theory on the Promotion and Maintenance of Exercise Behavior. Journal of Guilan University of Medical Sciences. 2012; 21(82): 46-56.

48) Hamrik Z, Sigmundová D, Kalman M, Pavelka J, Sigmund E. Physical activity and sedentary behavior in Czech adults: Results from the GPAQ study. Eur J Sport Sci. 2014; 14(2): 193-8. doi: 10.1080/17461391.2013.822565. PMID: 23889330, PMCID: PMC3935222.

49) Sweet SN, Fortier MS, Blanchard CM. Investigating motivational regulations and physical activity over 25 weeks. J Phys Act Health. 2013; 11(5): 1052-6. doi: 10.1123/jpah.2012-0057. PMID: 23799262.

50) Wilson PM, Rodgers WM. The relationship between perceived autonomy support, exercise regulations and behavioral intentions in women. Psychology of Sport and Exercise, 2004; 5: 229-42. doi: 10.1016/S14690292(03)00003-7.

51) Wininger SR. Self-determination theory and exercise behavior: An examination of the psychometric properties of the exercise motivation scale. Journal of Applied Sport Psychology. 2007; 19; 471-86. doi: $10.1080 / 10413200701601466$.

52) Fortier MS, Sweet SN, O’sullivan TL, Williams GC. A self-determination process model of physical activity adoption in the context of a randomized controlled trial. Psychology of Sport and Exercise. 2007; 8: 741-57. doi: 10.1016/j.psychsport.2006.10.006.

53) Edmunds J, Ntoumanis N, Duda JL. Testing a self - determination theory - based teaching style intervention in the exercise domain. European Journal of Social Psychology. 2007; 38 (2): 375-88. doi: 10.1002 /ejsp.463.

54) Vlachopoulos SP. Psychological Needs In Exercise Scale. In Community Exercise Programs: A CrossValidation Approach. Hellenic Journal of Psychology. 2007; 4: 52-74.

55) Levy SS, Cardinal BJ. Effects of a self-determination theory-based mail-mediated intervention on adults' exercise behavior. Am J Health Promot. 2004; 18(5): 345-9. doi: 10.4278/0890-1171-18.5.345. PMID: 15163133.

56) Fathi K, Ghorbani F, Heidarimoghadam R, Mojtahedi H. The effect of six- week aerobic step training on cardiovascular fitness, body composition, flexibility, anaerobic power and quality of life of female students of Isfahan University. Journal of Ergonomics. 2014; 2(2): 29-37.

57) Anbari S, Moghadasi M, Torkfar A, Rahimezadeh E, Khademi Y. The Effects of the Recommended Eightweeks sports-for-all Program on Physical Fitness and General Health of Male Employees. Armaghane danesh. 2012; 17(1): 40-9.

58) Fakourian A, Azarbaijani MA, Peeri M. Effect a period of selective military training on physical fitness, body mass index, mental health and mood in officer students. J Army Univ Med Sci. 2012; 10(1): 17-27. 